
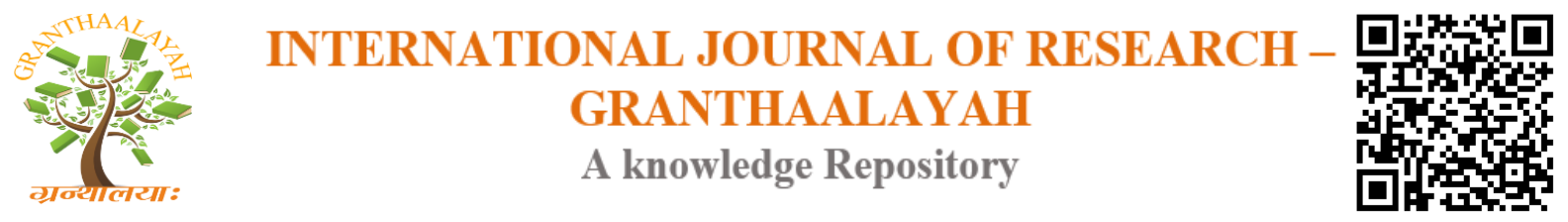

Science

\title{
EFFECTIVENESS OF FLIPPED CLASSROOM IN MATHEMATICS TEACHING
}

\author{
Dr. N. Ramakrishnan ${ }^{* 1}$, Mrs. J. Johnsi Priya ${ }^{2}$ \\ ${ }^{* 1}$ Professor and Head, Dept. of Educational Technology, Tamil Nadu Teachers Education \\ University Chennai- 600 097, INDIA \\ ${ }^{2}$ Assistant Professor in Education, Meston College of Education, Chennai, INDIA
}

DOI: https://doi.org/10.29121/granthaalayah.v4.i10(SE).2016.2469

\begin{abstract}
Flipped Classroom is an instructional strategy and a type of blended learning that reverses the traditional learning environment by delivering instructional content, often online, outside of the classroom. It moves activities, including those that may have traditionally been considered homework, into the classroom. In a flipped classroom, students watch online lectures, collaborate in online discussions, or carry out research at home and engage in concepts in the classroom with the guidance of a mentor. In traditional schools, each topic in class receives a fixed amount of time for all students. Flipped mastery classrooms apply a mastery learning model that requires each student to master a topic before moving to the next one. Flipped classroom will be most suitable for mathematics teaching as parents are not in a position to teach their wards on some mathematical problems working in the classroom with teacher will help them a lot. Hence, the investigators though of conducting an experiment study on Flipped classroom on mathematics teaching. The investigator being a mathematics teacher herself prepared a video lesson on Area and Perimeter one of the units in Mathematics subject of IX std. in Tamil Nadu state Board syllabus. The experiment was conducted in Govt. School in Chennai. The finding of the study reveals that flipped classroom has positively affected IX std. students' achievement in mathematics.
\end{abstract}

Keywords:

Effectiveness, Flipped classroom, Mathematics, Teaching.

Cite This Article: Dr. N. Ramakrishnan, and Mrs. J. Johnsi Priya, "EFFECTIVENESS OF FLIPPED CLASSROOM IN MATHEMATICS TEACHING” International Journal of Research - Granthaalayah, Vol. 4, No. 10: SE (2016): 57-62. 


\section{INTRODUCTION}

\section{NEED FOR THE STUDY}

Flipped Classroom is an instructional strategy and a type of blended learning that reverses the traditional learning environment by delivering instructional content, often online, outside of the classroom. In traditional schools, each topic in class receives a fixed amount of time for all students. Flipped mastery classrooms apply a mastery learning model that requires each student to master a topic before moving to the next one. Mastery learning was briefly popular in the 1920s, and was revived by Benjamin Bloom in 1968. While it is difficult to implement in large, traditional classrooms, it has shown dramatic success in improving student learning. The mastery model allows teachers to provide the materials, tools and support for learning while students set goals and manage their time. Mastery rewards students for displaying competence. Students who initially turn in shoddy work must correct it before moving on. Before flipping, mastery learning was impractical in most schools. It was not possible to give different lectures for different groups of students. Testing was also impractical, because fast-learning students could reveal the test to those who followed. In a flipped mastery classroom, students view each lecture and work on each exercise or project when they have mastered the precursors. Tim Kelly, winner of the Presidential Award for Mathematics and Science Teaching, adopted flipped mastery with his colleagues Corey Sullivan and Mike Brust. Sullivan estimated that 40 to 60 hours of work outside school for each of 12 units per course were required the first year. Another Presidential Award winner, Spencer Bean, converted after his daughter went through Kelly's class. Flipped mastery eliminates two other out-of-class routines: daily lesson planning and grading papers. The latter happens in class and in person. Replacing lectures with group and individual activities increases in-class activity. Every student has something to do throughout the class. In some classes, students choose how to demonstrate mastery - testing, writing, speaking, debating and even designing a related game. Moodle provides one way to manage the testing process. It creates a different test for each student from a pool of questions. Advocates claim that its efficiency allows most students to do a year's work in much less time. Advanced students work on independent projects while slower learners get more personalized instruction. Some students might not get through the year's material, but demonstrated competence on the parts they did complete. Flipped classroom will be most suitable for mathematics teaching as parents are not in a position to teach their wards on some mathematical problems working in the classroom with teacher will help them a lot. Hence, the investigators though of conducting an experiment study on Flipped classroom on mathematics teaching.

\section{TERMS AND DEFINITIONS}

EFFECTIVENESS- refers to the result of independent variable introduced in the study.

FLIPPED CLASSROOM - refers to a type of blended learning that reverses the traditional learning environment by delivering instructional content, often online, outside of the classroom. It moves activities, including those that may have traditionally been considered homework, into the classroom. 
MATHEMATICS TEACHING - refers to teaching mathematics as a subject for school students from I std to XII std.

\section{OBJECTIVES OF THE STUDY}

The Study has been attempted with the following objectives;

1) To develop a video lesson on Area and Perimeter in the Mathematics unit from IX std. Tamil Nadu State board Syllabus

2) To validate the video lesson on Area and Perimeter in the Mathematics Unit from IX std. Tamil Nadu State board Syllabus

3) To prepare a criterion test on Area and Perimeter in the Mathematics Unit from IX std. Tamil Nadu State board Syllabus

4) To validate the criterion test on Area and Perimeter in the Mathematics Unit from IX std. Tamil Nadu State board Syllabus

5) To find out the effectiveness of Flipped classroom on Area and Perimeter in the Mathematics achievement of IX std. Students.

\section{HYPOTHESIS FORMULATED FOR THE STUDY}

The investigator has formulated the following hypothesis for the study.

There is no significant difference in the mean scores on Criterion Test on Area and Perimeter of Mathematics Unit from IX std. between Pretest and Posttest of experimental group students.

\section{LIMITATIONS OF THE STUDY}

The study was confined only to the Flipped Classroom module developed and validated on Area and Perimeter in the Mathematics unit of IX std. syllabus of Tamil Nadu Textbook Society. The study was taken only for IX standard students following Tamil Nadu State Board Syllabus.

The experiment was conducted only in the urban center. Rural area students have not been included in the study. The IX std. Matriculation, CBSE, ICSE and other streams have not been taken into consideration for the present study. The study was conducted only with English medium students of IX standard syllabus of Tamil Nadu Textbook Society. The Tamil medium students of IX standard students were not taken into consideration for this study.

\section{METHODOLOGY}

\section{DESIGN OF THE STUDY}

A worthwhile research project is likely to result from a well formulated research design. The design can be equated to a blue print which provides a clear cut guidelines to the investigator in carrying out his/her research successfully. In the present study, the investigator developed and validated Flipped Classroom on Area and Perimeter in the Mathematics unit of IX std. To achieve the objectives the investigator has chosen a pretest - posttest experimental only group design. The Schematic presentation of the design for the present study is given in Table 1. 
Table 1: Schematic Presentation of Research Design

\begin{tabular}{|c|c|c|c|c|}
\hline \multicolumn{5}{|c|}{ It is a pretest -posttest Experimental group only design } \\
\hline \multicolumn{4}{|l|}{ 1.Independent Variable } & $\begin{array}{l}\text { Learning the Area and Perimeter in } \\
\text { the Mathematics Unit of IX std. } \\
\text { through Flipped Classroom Module - } \\
\text { Experimental Group }\end{array}$ \\
\hline \multicolumn{4}{|l|}{ 2. Dependent Variable } & $\begin{array}{l}\text { Criterion Test on Area and Perimeter } \\
\text { in the Mathematics Unit. }\end{array}$ \\
\hline \multicolumn{5}{|l|}{ II TOOLS USED } \\
\hline \multicolumn{4}{|l|}{ Name of the Tool } & Purpose \\
\hline \multicolumn{4}{|c|}{$\begin{array}{l}\text { 1. Achievement Test on Area and Perimeter in the } \\
\text { Mathematics Unit. }\end{array}$} & $\begin{array}{l}\text { To measure the achievement of the } \\
\text { IX std. students in the unit Area and } \\
\text { Perimeter in the Mathematics Unit. }\end{array}$ \\
\hline \multicolumn{4}{|c|}{$\begin{array}{l}\text { 2. Stimulus Materials Used : Flipped Classroom on Area } \\
\text { and Perimeter in the Mathematics Unit. }\end{array}$} & As the treatment variable \\
\hline \multicolumn{4}{|l|}{ III SAMPLES SELECTED } & \\
\hline \multicolumn{4}{|l|}{ For conducting Experiment } & \\
\hline \multirow[t]{2}{*}{ Group } & \multicolumn{3}{|c|}{ No. of Students } & \multirow[t]{2}{*}{ School } \\
\hline & Boys & Girls & Total & \\
\hline $\begin{array}{l}\text { Experimental } \\
\text { (Flipped Classroom on } \\
\text { Area and Perimeter in the } \\
\text { Mathematics Unit. ) }\end{array}$ & 20 & 20 & 40 & $\begin{array}{l}\text { Lady Willingdon Govt. Girls Hr. } \\
\text { Sec. School }\end{array}$ \\
\hline
\end{tabular}

\section{ITEM ANALYSIS OF CRITERION TEST ON MATHEMATICS UNIT}

Item analysis is done in order to improve the reliability and validity of the test. In item analysis the difficulty level and discriminative index of the test items were found.

\section{DATA COLLECTION}

Being an experimental study the data had to be generated, unlike the survey. It is a pre-test post-test Experimental group only design. The sample selected for conducting the experiment was presented under Table 1. 


\section{DATA ANALYSIS}

The investigator applied ' $t$ ' tests between pre and post test scores of Criterion Test on Area and Perimeter in the Mathematics Unit.

\section{Hypothesis 1}

There is no significant difference in the mean scores on Criterion Test on Area and Perimeter in the Mathematics Unit between pre and posttest of experimental group of IX std. students.

Table 2 presents the ' $t$ ' test results on the Criterion Test on Area and Perimeter in the Mathematics Unit between pre and posttests of experimental group.

Table 2: Significance of Difference in the Mean Achievement of Criterion Test on Area and Perimeter in Mathematics between Pre and Post Tests of Experimental Group

\begin{tabular}{|l|l|l|l|l|l|l|}
\hline Group & $\mathrm{N}$ & MEAN & S.D. & 't' & DF & $\begin{array}{l}\text { Level of } \\
\text { Significance }\end{array}$ \\
\hline Pre- Test & 40 & 58 & 10.56 & & & \\
\cline { 1 - 6 } Post -Test & 40 & 69 & 11.36 & 4.695 & 78 & 0.01 \\
\hline
\end{tabular}

It is evident from Table 2 that the ' $t$ ' value between the Pretest and Posttest of experimental group in the Criterion Test on Area and Perimeter in Mathematics is 4.695. It is significant at 0.01 and 0.05 level for the df 78. The mean of Posttest of Experimental group (69) is higher than the mean of Pretest of Experimental group (58). Therefore the null hypothesis stated is rejected. It can be inferred that the Flipped Classroom on Area and Perimeter in the Mathematics Unit has positively affected the students' achievement in Mathematics.

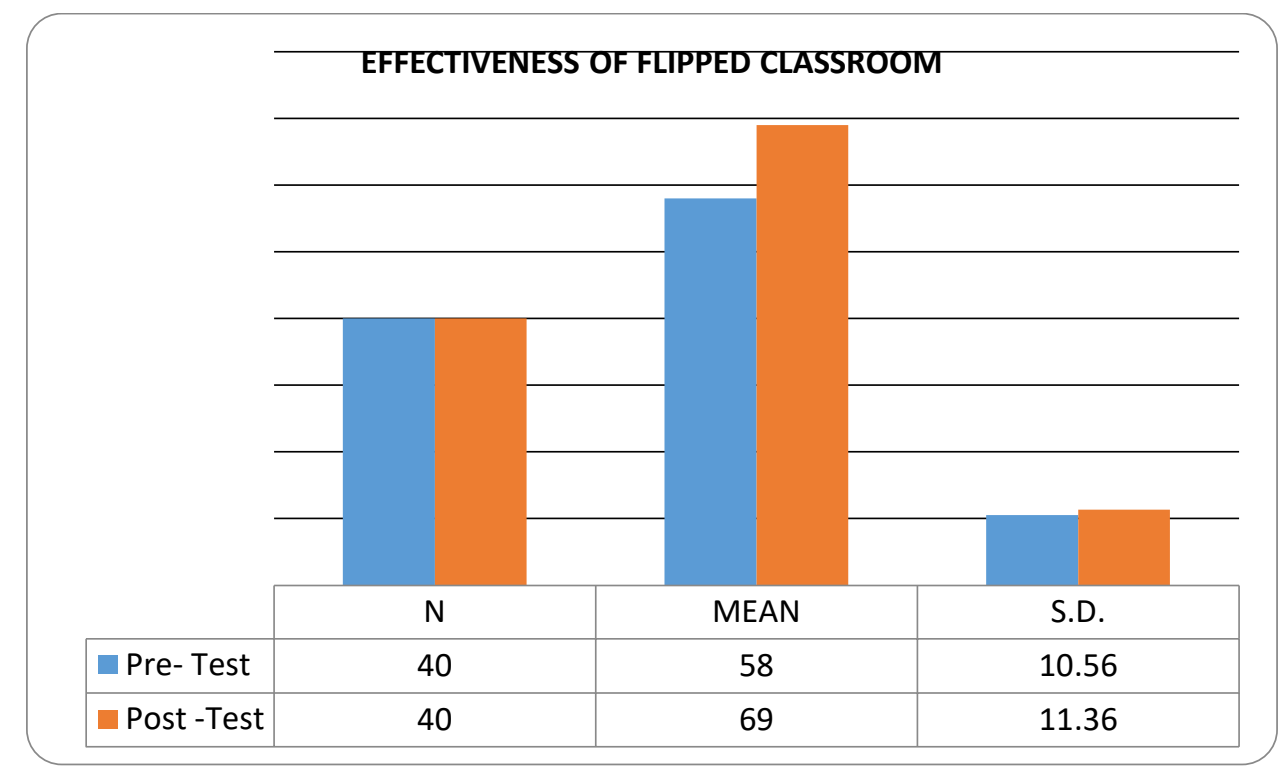

Figure 1: Figure Showing the Significance of Difference in the Mean Achievement of Criterion Test on Area and Perimeter in Mathematics between Pre and Post Tests of Experimental Group 


\section{FINDING OF THE STUDY}

The Flipped Classroom on Mathematics unit has affected positively on Students achievement in Mathematics.

\section{CONCLUSION}

The present finding is derived from the experiment conducted before and after flipped classroom. Based on the attempts made by the investigator and the findings of the related studies, the investigator feels that far reaching conclusions could not be arrived at. As discussed earlier, the present study has attempted to find out the effect of Flipped Classroom on Area and Perimeter in the In order to find out the effectiveness the investigator has developed and validated Flipped Classroom Module on Area and Perimeter in the in the Mathematics Unit. Further to assess the effectiveness of the developed Flipped Classroom on IX std. students' achievement in Mathematics constructed and validated a Criterion Test on Area and Perimeter in the Mathematics Unit. From the perusal of the present findings the following conclusion can be drawn. The Flipped Classroom module on Area and Perimeter in the Mathematics Unit has affected the students' achievement in Mathematics.

\section{EDUCATIONAL IMPLICATIONS}

The study has come out with the finding that the flipped classroom has affected students' achievement in mathematics. Therefore the Mathematics teachers may be given training in preparing video lessons on mathematics units and may be allowed to send it to students through modern apps like whats app etc. The students may learn the lesson at home at their own speed. The homework can be done at classroom. Practically it has helped a lot for students. Particularly to the Govt. School students like the present sample of Lady Willingdon where parents are uneducated may not be able to support their children at home in doing homework that too in mathematics will be a of great help to the student community and in turn to the society.

\section{REFERENCES}

[1] The flip: Turning a classroom upside down, Washington Post, 4. June, 2012.

[2] Abeysekera, Lakmal, and Phillip Dawson (2015). "Motivation and cognitive load in the flipped classroom: definition, rationale and a call for research." Higher Education Research \& Development 34(1), 1-14.

[3] Golden, S. A. R. (2011). Problems and Prospectus of Distance Learning. Bharathidhasan University, 343, 344.

[4] Marco Ronchetti (June 2010), "Using video lectures to make teaching more interactive", International Journal of Emerging Technologies in Learning (iJET)

[5] Greg Topp (6 Oct 2011), "Flipped classrooms take advantage of technology.

[6] Golden, S. A. R. (2016). Rural Students' Attitude towards English as Medium of Instruction in Higher Education - An Analysis, International Journal of Research, Vol 03, spl Issue - 16, pp, 2- 9. 